\title{
Loss of glucocerebrosidase 1 activity causes lysosomal dysfunction and $\alpha$-synuclein aggregation
}

\author{
Eun-Jin Bae ${ }^{1,2}$, Na Young Yang ${ }^{1,2,7}$, Cheolsoon Lee ${ }^{2,3}$, He-Jin Lee ${ }^{2,3}$, Seokjoong Kim ${ }^{4}$, Sergio Pablo Sardi ${ }^{5}$ and \\ Seung-Jae Lee ${ }^{1,2,6}$
}

Lysosomal dysfunction is a common pathological feature of neurodegenerative diseases. GTP-binding protein type A1 (GBA1) encodes $\beta$-glucocerebrosidase 1 (GCase 1), a lysosomal hydrolase. Homozygous mutations in GBA1 cause Gaucher disease, the most common lysosomal storage disease, while heterozygous mutations are strong risk factors for Parkinson's disease. However, whether loss of GCase 1 activity is sufficient for lysosomal dysfunction has not been clearly determined. Here, we generated human neuroblastoma cell lines with nonsense mutations in the GBA1 gene using zinc-finger nucleases. Depending on the site of mutation, GCase 1 activity was lost or maintained. The cell line with GCase 1 deficiency showed indications of lysosomal dysfunction, such as accumulation of lysosomal substrates, reduced dextran degradation and accumulation of enlarged vacuolar structures. In contrast, the cell line with C-terminal truncation of GCase 1 but with intact GCase 1 activity showed normal lysosomal function. When $\alpha$-synuclein was overexpressed, accumulation and secretion of insoluble aggregates increased in cells with GCase 1 deficiency but did not change in mutant cells with normal GCase 1 activity. These results demonstrate that loss of GCase 1 activity is sufficient to cause lysosomal dysfunction and accumulation of $\alpha$-synuclein aggregates.

Experimental \& Molecular Medicine (2015) 47, e153; doi:10.1038/emm.2014.128; published online 27 March 2015

\section{INTRODUCTION}

Parkinson's disease (PD) is one of the most common neurodegenerative diseases, with clinical symptoms of resting tremor, increased muscle tone, bradykinesia and abnormal postural righting reflexes. ${ }^{1}$ Pathologically, PD is characterized by loss of dopaminergic neurons in the substantia nigra pars compacta; deposition of $\alpha$-synuclein, visualized in the form of Lewy bodies (LBs) and Lewy neurites and neuroinflammation, demonstrated by the activation of microglia. ${ }^{2}$ In addition to these features, neurons of patients with PD show signs of extensive lysosomal dysfunction, such as accumulation of autophagosomes, a characteristic also seen in other neurodegenerative diseases. $^{3}$

Genetic studies of PD have identified several genes and loci in inherited cases. ${ }^{4}$ Recently, genome-wide association studies have identified several risk loci for PD, suggesting that susceptibility to PD (even sporadic PD) is determined by specific allelic combinations. ${ }^{5-8}$ Although some of these genes operate independently, ${ }^{9}$ there might be interactions among these genes in the pathogenesis of PD. Among the susceptibility loci, the ones most strongly and consistently associated with sporadic PD have been located in SNCA, the gene encoding $\alpha$-synuclein. ${ }^{6,7}$

Gaucher disease (GD), the most common lysosomal storage disease with recessive inheritance is mainly due to loss-offunction of the lysosomal enzyme, glucocerebrosidase (GCase). ${ }^{10}$ About 300 different mutations in GTP-binding protein type A1 (GBA1) gene, encoding GCase1, are known to cause GD. ${ }^{11}$

Recent studies have suggested the association between mutations in GBA1 and parkinsonism. Genetic studies have shown that heterozygous carriers of mutations in GBA1 are at higher risk for PD than the general population. ${ }^{12}$ For example, patients with $\mathrm{PD}$ are approximately five times more likely to carry GBA1 mutations than healthy control subjects. ${ }^{13}$ Compared with control group, the incidence of parkinsonism is increased 6- to 17-folds in patient group with type1 GD. ${ }^{14}$ Brain samples from patients with PD and dementia with LBs with a heterozygous GBA1 mutation showed a mean of $75 \%$ (range, 32-90\%) of LBs colocalized with GCase, whereas the

${ }^{1}$ Department of Biomedical Science and Technology, Konkuk University, Seoul, Korea; ${ }^{2}$ Institute of Biomedical Science and Technology, Konkuk University, Seoul, Korea; ${ }^{3}$ Department of Anatomy, School of Medicine, Konkuk University, Seoul, Korea; ${ }^{4}$ ToolGen, Biotechnology Incubating Center, Seoul National University, Seoul, Korea; ${ }^{5}$ Genzyme, Framingham, MA, USA and ${ }^{6}$ College of Veterinary Medicine, Konkuk University, Seoul, Korea

${ }^{7}$ Current Address: Cook Medical Korea, Seoul 150-737, Korea

Correspondence: Professor S-J Lee, Department of Biomedical Science and Technology, Konkuk University, Room 706, Biomedical Research Building, 120 Neungdong-ro, Gwangjin-gu, Seoul 143-701, Korea.

E-mail: sjlee@konkuk.ac.kr

Received 6 August 2014; revised 27 November 2014; accepted 4 December 2014 
mean colocalization rate was $4 \%$ in patients with $\mathrm{PD}$ and dementia with $\mathrm{LB}$ without a GBA1 mutation. ${ }^{15}$ In addition, patients with GD and GD carriers with parkinsonism have LB pathology. ${ }^{16}$ These results suggest a strong and specific association between GBA1 mutations and LB diseases (LBDs).

Despite the strong association of GBA1 mutations with PD and other LBDs, the mechanism underlying the role of these mutations in PD is not clearly understood. Here, we generated human neuroblastoma cell lines harboring nonsense mutations in the GBA1 gene and analyzed the effects of these mutations on lysosomal function and $\alpha$-synuclein aggregation.

\section{MATERIALS AND METHODS}

\section{Materials}

The following antibodies were used in this study: GCase monoclonal antibody 8E4 (from J Barranger, University of Pittsburgh; 1:1000), GCase polyclonal antibody (G4171, Sigma-Aldrich, St Louis, MO, USA; 1:1000), $\beta$-actin monoclonal antibody (Sigma-Aldrich; 1:10 000), p62 monoclonal antibody (c2384-0B, BD Transduction Laboratories, Swampscott, MA, USA; 1:1000), ubiquitin polyclonal antibodies (Dako, Glostrup, Denmark and Chemicon, Temecula, CA, USA; 1:1000), $\alpha$-synuclein monoclonal antibody (610787, BD Biosciences; $1: 1500), \quad \alpha$-synuclein monoclonal antibody Ab274 (1:1500), ${ }^{17}$ $\alpha$-synuclein monoclonal antibody Ab62 (1:1000), ${ }^{17}$ Horse radish peroxidase (HRP)-conjugated goat anti-mouse immunoglobulin G (IgG; H+L) (172-1011, Bio-Rad Laboratories, Hercules, CA, USA; 1:3000) and HRP-conjugated goat anti-rabbit IgG $(\mathrm{H}+\mathrm{L})$ (Bio-Rad Laboratories; $1: 3000)$.
Fluorescein-conjugated dextran (10 000 molecular weight; D-1821), TO-PRO-3 iodide (T3605) and LysoTracker Red DND-99 (L-7528) were purchased from Invitrogen (Carlsbad, CA, USA).

\section{Generation of GBA1 knockout cell lines}

SH-SY5Y cells (CRL-2266, ATCC, Manassas, VA, USA) were transfected with plasmids encoding zinc-finger nuclease (ZFN) and a magnetic reporter (ToolGen, Seoul, Korea) by using electroporation. After incubation for $48 \mathrm{~h}$, cells were enriched by magnetic separation. After trypsinization, cells were mixed with magnetic bead-conjugated antibody against $\mathrm{H}-2 \mathrm{~K}^{\mathrm{k}}$ (MACSelect Kk microbeads, Miltenyi Biotech, Gladbach, Germany), and the mixture was applied to a MACS LS column (Miltenyi Biotech). Single cells were isolated from the eluates and maintained until the clonal colonies were picked from the culture dish. Nonsense mutations in the GBA1 gene were confirmed by DNA sequencing. Four clones with nonsense mutations in exon 3 and six clones in exon 11 were generated. Among these clones, three clones with mutation in exon 3 and two clones with mutations in exon 11 were further analyzed.

\section{Cell culture}

SH-SY5Y human neuroblastoma cell lines were cultured as described previously. ${ }^{18}$ Cells were maintained every 2 days at $37^{\circ} \mathrm{C}$ in humidified air with $5 \% \mathrm{CO}_{2}$ in Dulbecco's modified eagle's medium (DMEM) (SH30243.01, HyClone, Logan, UT, USA) containing 10\% fetal bovine serum (SH30396.03, HyClone), $100 \mathrm{U} \mathrm{ml}^{-1}$ penicillin and $100 \mathrm{U} \mathrm{ml}^{-1}$ streptomycin (15140-122, Gibco, Grand Island, NY, USA). To differentiate SH-SY5Y cells, cells were maintained in medium with $50 \mu \mathrm{M}$ all-trans-retinoic acid (R2625, Sigma-Aldrich). For overexpression of human $\alpha$-synuclein, differentiated SH-SY5Y

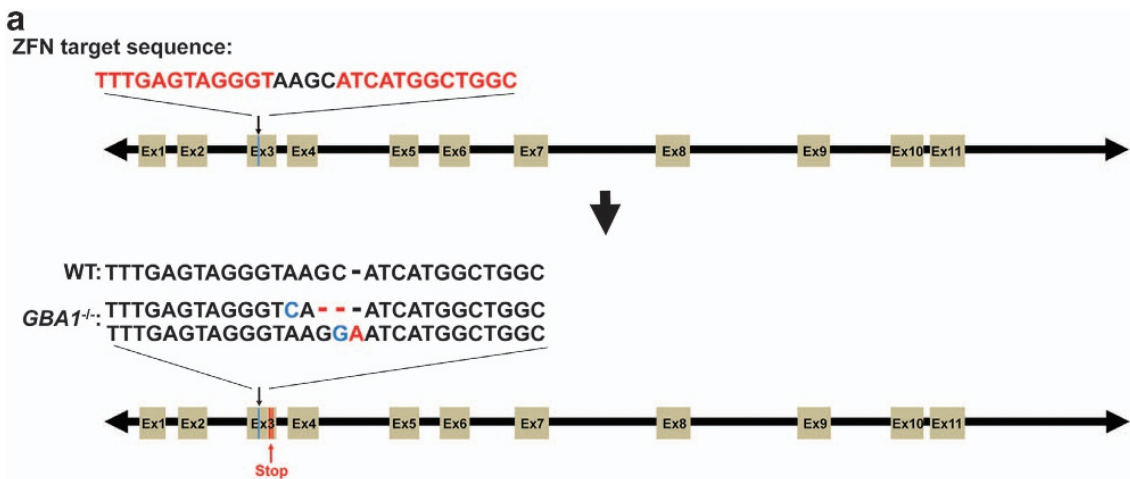

b

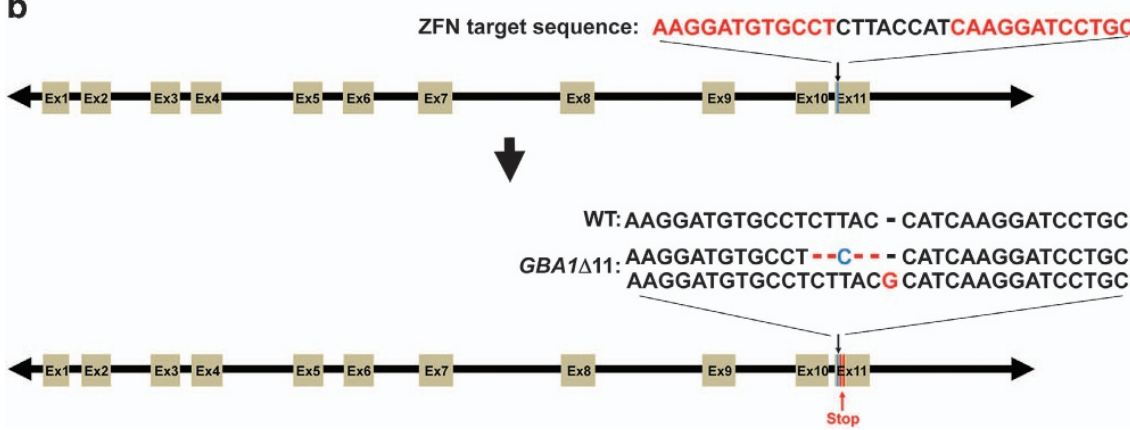

Figure 1 Generation of frame-shift mutations in GTP-binding protein type A1 (GBA1) by using zinc-finger nucleases (ZFNs). To generate nonsense mutations in two alleles of the GBA1 gene, SH-SY5Y cells were transfected with ZFNs targeting either exon 3 (a) or exon 11 (b). After clonal selection, the nonsense mutations were confirmed by DNA sequencing. 
cells were infected with a recombinant adenoviral vector (serotype Ad5, cytomegalovirus promoter) containing human $\alpha$-synuclein complementary DNA at a multiplicity of infection of 33.3.

\section{GCase activity and glycosphingolipid assay}

Cellular GCase activity was determined as described previously. ${ }^{19}$ Briefly, GCase activity was determined using a synthetic substrate, $10 \mathrm{~mm}$ 4-methylumbelliferyl- $\beta$-D-glucoside (Sigma, St Louis, MO, USA) in buffer containing $1 \%$ bovine serum albumin, at $37^{\circ} \mathrm{C}$ for $1 \mathrm{~h}$. To stop the reaction, 0.5 volume of $1 \mathrm{~m}$ glycine buffer, $\mathrm{pH} 12.5$, was added. Cleaved 4-methylumbelliferone was measured using a SpectraMax Gemini fluorometer (excitation at $365 \mathrm{~nm}$, emission at $445 \mathrm{~nm}$; Molecular Devices, Sunnyvale, CA, USA). All measurements were done without taurocholate, a detergent that activates GCase. GCase 1 and GCase 2 activity was determined in the presence of either a GCase 1 inhibitor, conduritol-B-epoxide (CBE) or a GCase 2 inhibitor, AMP-deoxynojirimycin. GCase 1 activity was obtained by subtracting the GCase 2 activity from the total GCase activity. Cellular glucocerebroside (GL1) and galactocerebroside (GalCer) levels were measured by mass spectrometry as previously described. ${ }^{19}$ Briefly, organic cellular extracts were injected into an Atlantis HILIC silica column (Waters, Milford, MA, USA), and the separated GL1 and GalCer were detected using an AB Sciex API-5000 mass spectrometer (AB Sciex, Framingham, MA, USA).

\section{Preparation of cell extracts}

Cells were washed twice with ice-cold phosphate-buffered saline (PBS) and then lysed in extraction buffer (1\% Triton X-100 and 1\% (v/v) protease inhibitor cocktail (Sigma) in PBS). Cell lysates were incubated on ice for $10 \mathrm{~min}$ and centrifuged at $16000 \mathrm{~g}$ for $10 \mathrm{~min}$. The Triton $\mathrm{X}-100$ insoluble fraction was resuspended in $1 \times$ Laemmli sample buffer and sonicated briefly.

\section{Western blotting}

Western blotting was performed as previously described. ${ }^{20}$ Images were obtained and quantified using a Luminescent Image Analyzer (Fuji Film, Tokyo, Japan) (LAS-3000) and MultiGauge version 3.0 software (Fujifilm).

\section{Characterization of lysosomal dysfunction}

To analyze the LysoTracker-positive compartments, SH-SY5Y cells were stained with $75 \mathrm{~nm}$ LysoTracker solution diluted in growth medium. After incubation for $1 \mathrm{~h}$ at $37^{\circ} \mathrm{C}$ in a $\mathrm{CO}_{2}$ incubator, cells were washed with ice-cold PBS and fixed in a $4 \%$ paraformaldehyde solution. To determine the degradation ratio of internalized dextran, cells were incubated with $20 \mu \mathrm{g} \mathrm{ml}^{-1}$ fluorescein isothiocyanatelabeled dextran (Invitrogen) for $2 \mathrm{~h}$. After washing with DMEM, cells were incubated with fresh growth medium for 30 min and fixed with a $4 \%$ paraformaldehyde solution. The fluorescence intensity was measured using Olympus FV1000 software (Olympus, Tokyo, Japan). The extent of degradation of internalized dextran-fluorescein isothiocyanate was calculated using the equation $\left(F_{\text {time } 0}-F_{\text {time30 }}\right) /$ $F_{\text {time0 }}$, where $F_{\text {time0 }}$ and $F_{\text {time30 }}$ are the integrated fluorescence intensities at $0 \mathrm{~min}$ and $30 \mathrm{~min}$, respectively.

\section{Electron microscopy}

Cells were fixed with Karnovsky's fixative solution (2\% glutaraldehyde, $2 \%$ paraformaldehyde and $0.5 \% \mathrm{CaCl}_{2}$ ). After immersion in $1 \%$ osmium tetraoxide for $1.5 \mathrm{~h}$, cells were dehydrated with $50,60,70,80$, 90, 95 and 100\% absolute ethanol. Cells were infiltrated with propylene oxide and EPON mixture (EPON 812, MNA, DDSA, DMP30) for 10 min before being embedded in EPON mixture. After embedding, cells were sectioned with an EM UC-7 Ultramicrotome (Leica Microsystems, Vienna, Austria) and stained with 6\% uranyl acetate and lead citrate. Grids were observed using a transmission electron microscope (JEM-1011, JEOL, Tokyo, Japan) and analyzed using MegaView III software (Soft Imaging System, Münster, Germany). For morphometric analysis, 20 cells were analyzed for each experiment.

\section{Enzyme-linked immunosorbent assay}

Enzyme-linked immunosorbent assay (ELISA) was performed as previously described. ${ }^{17}$ Briefly, 96-well ELISA plates (Nalge Nunc International, Rochester, NY, USA) were coated with $1 \mathrm{mg} \mathrm{ml}^{-1}$ capture antibody (Ab62) in $50 \mathrm{~mm}$ carbonate buffer (pH 9.6) at $4{ }^{\circ} \mathrm{C}$ overnight. After washing with PBS with $0.05 \%$ Tween 20 (PBST), SuperBlock T20 (PBS) Blocking Buffer (Thermo Scientific, Rockford, IL, USA) was added for $1 \mathrm{~h}$ at room temperature with shaking. Plates were washed five times in PBST and samples and standards were incubated at room temperature for $2.5 \mathrm{~h}$ with shaking. After washing

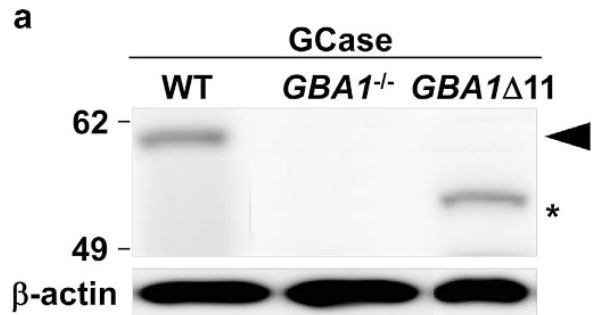

b
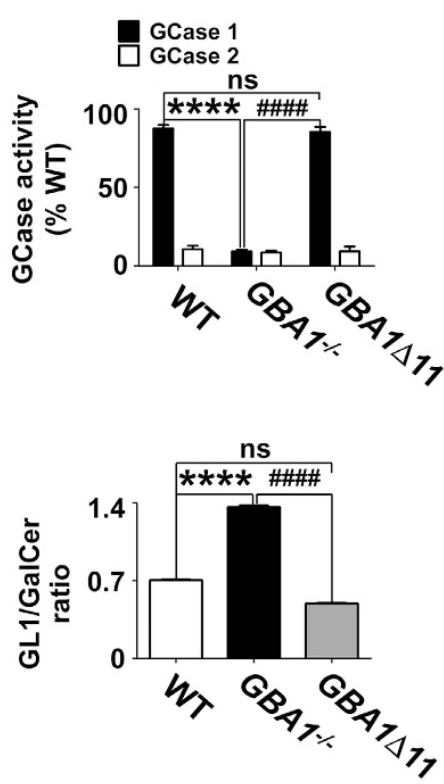

Figure 2 Confirmation of GTP-binding protein type A1 (GBA1) deficiency. (a) Western blot analysis of glucocerebrosidase 1 (GCase 1) in Triton-soluble fractions. Arrowhead: GCase1, asterisk: C-terminal truncated GCase1. (b) Analysis of GCase activity ( $n=4$; $* * * * P<0.0001$, \#\#\#\# $P<0.0001$ by paired, two-tailed Student's $t$-test). (c) Accumulation of GCase substrate. Substrate accumulation was assessed by the glucocerebroside (GL1) to galactocerebroside

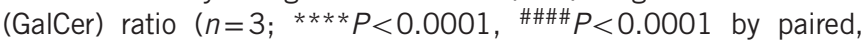
two-tailed Student's $t$-test). NS, not significant. 
with PBST, $1 \mu \mathrm{g} \mathrm{ml}^{-1}$ biotinylated Ab62 in blocking buffer was added and incubated at room temperature for $1.5 \mathrm{~h}$. The plates were washed with PBST, and avidin-conjugated peroxidase (ExtrAvidin, Sigma) was added for $1 \mathrm{~h}$ at room temperature. After washing with PBST, $100 \mu \mathrm{l}$ of 3,3',5,5'-tetramethylbenzidine solution (Sigma) was added to each well and incubated for $15 \mathrm{~min}$ with shaking. To stop the reaction, $50 \mu \mathrm{l}$ of $2 \mathrm{~N} \mathrm{H}_{2} \mathrm{SO}_{4}$ was added to each well. The absorbance was measured at $450 \mathrm{~nm}$.

\section{Statistical analysis}

Values shown in the figures are mean \pm s.e.m. To analyze the statistical significance, $P$-values were calculated by mean of paired, two-tailed
Student's $t$-tests by using InStat version 3.05 software (GraphPad Software, San Diego, CA, USA).

\section{RESULTS}

To address the effects of loss-of-function of GCase1 activity on the lysosomal function and the metabolism of $\alpha$-synuclein, we have generated SH-SY5Y human neuroblastoma cell lines with nonsense mutations in both copies of the GBA1 gene using engineered ZFNs. The GBA gene comprises 11 exons and 10 introns. The coding regions of enzymatic active site is located in exon 5-10. ${ }^{11}$ The ZFNs were designed to generate mutations at two different sites in the coding region of $G B A 1$, one in exon a
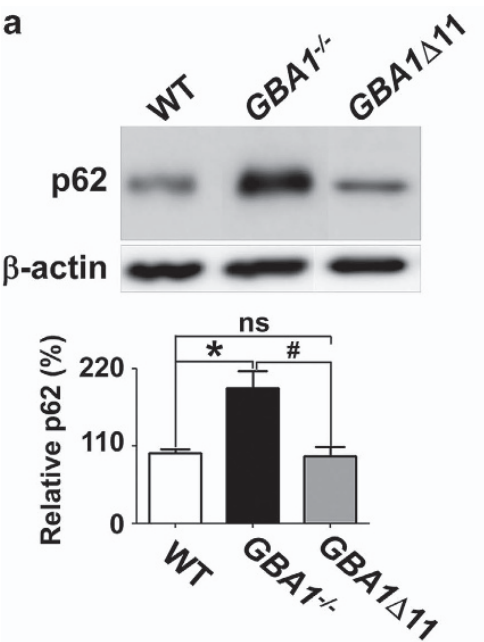

C
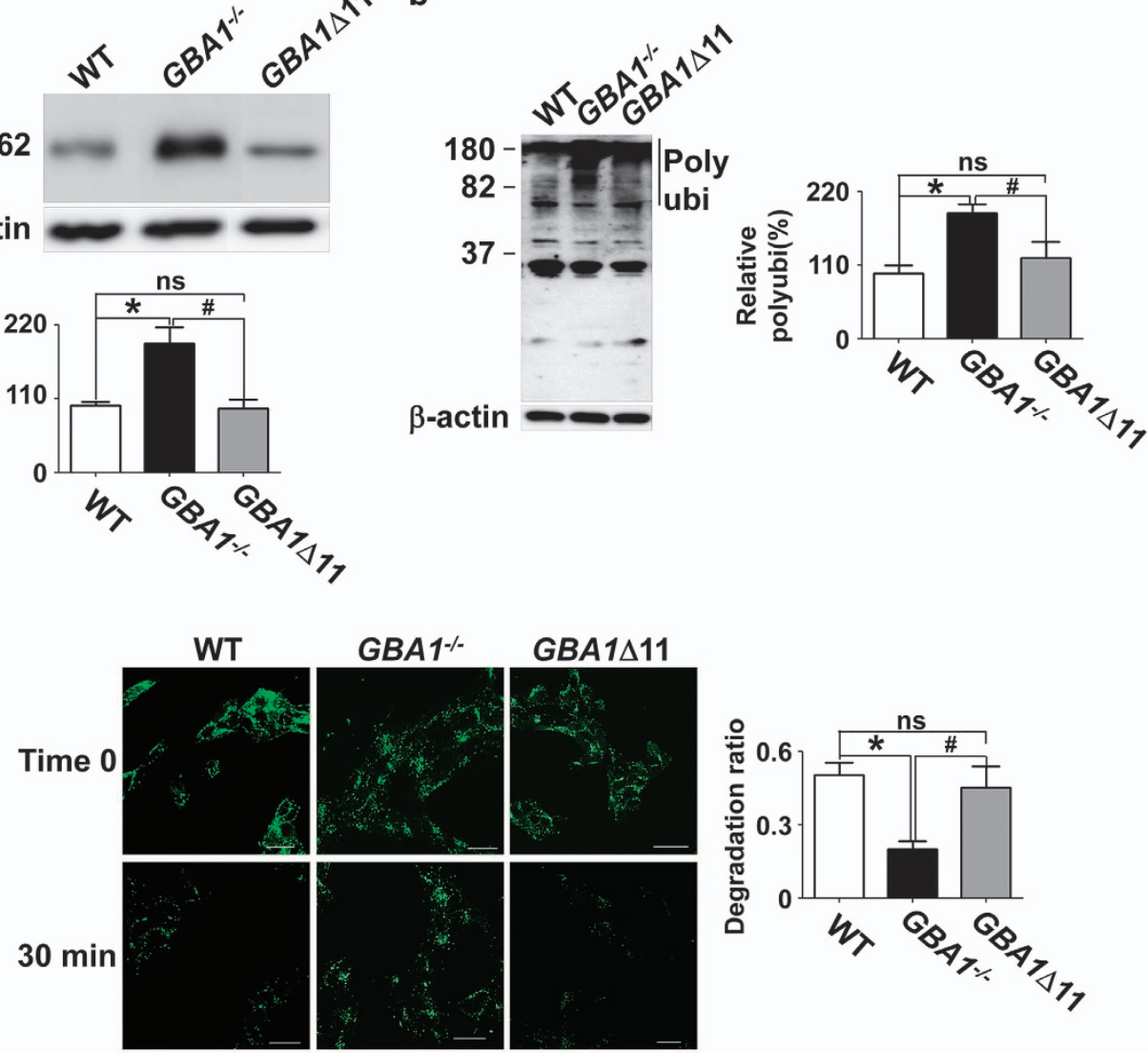

d

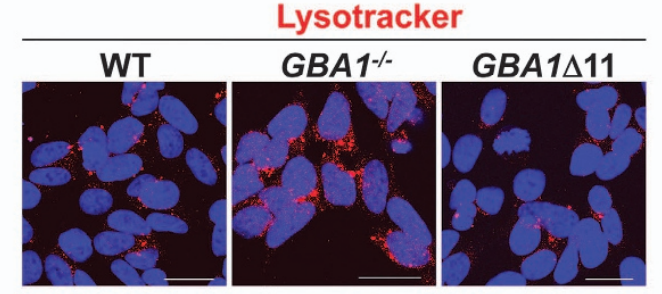

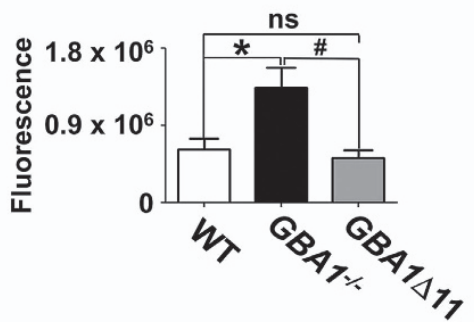

Figure 3 GTP-binding protein type A1 (GBA1) deficiency induces lysosomal dysfunction. (a, b) Levels of p62 (a) and polyubiquitinated proteins (b) in Triton-insoluble fractions $\left(n=3 ;{ }^{*} P<0.05\right.$, ${ }^{\#} P<0.05$ by paired, two-tailed Student's $t$-test). For quantification of polyubiquitinated proteins, the quantified size range is indicated by the line to the right of the blot. (c) Degradation of internalized dextran-fluorescein isothiocyanate ( $n=3,100$ cells per experiment; ${ }^{*} P<0.05$, ${ }^{\#} P<0.05$ by paired, two-tailed Student's $t$-test). Scale bars, $20 \mu \mathrm{m}$. (d) Quantification of LysoTracker-positive compartments $\left(n=3,100\right.$ cells per experiment; ${ }^{*} P<0.05$, ${ }^{\#} P<0.05$ by paired, twotailed Student's $t$-test). Scale bars, $20 \mu \mathrm{m}$. NS, not significant. 
3 and the other in exon 11. Clonal cell lines with nonsense mutations at the intended sites were screened and selected by sequencing (Figure 1). We generated four clones with nonsense mutation in exon 3 and six clones with nonsense mutation in exon 11. To analyze the lysosomal activity, we selected three clones with mutations in exon 3 and two clones with mutations in exon 11. Results from the isogenic clones were identical. Western analysis showed that the translational stop codon in exon 3 caused a loss of GCase 1 expression $\left(G B A 1^{-/-}\right)$, whereas the translational termination signal in exon 11 resulted in a truncated form of GCase 1 (GBA1D11) (Figure 2a). GBA1D11 contains all the regions necessary for catalytic activity. ${ }^{21,22}$ To address the effects of missense mutations in GBA1 on the GCase activity, we evaluated the catalytic activity of GCase 1 and 2 in the presence of either GCase 1 inhibitor, $\mathrm{CBE}$, or GCase 2 inhibitor, AMP-deoxynojirimycin. AMPdeoxynojirimycin-sensitive GCase 2 activity was much lower than CBE-sensitive GCase 1 activity. About $90 \%$ of the total GCase activity was derived from GCase 1 and $\sim 2 \%$ from GCase 2, the cytosolic form of GCase encoded by a separate gene GBA2. ${ }^{23}$ As expected, GBA1 $\Delta 11$ cells and wild-type cells showed similar levels of GCase activity. In contrast, GBA1 ${ }^{-1-}$ cells had a greatly reduced level of GCase activity (Figure $2 b$ ). The residual activity detected in $G B A 1^{-1-}$ cells was contributed by AMP-deoxynojirimycin-sensitive GCase 2 activity. As a result of reduced GCase activity, $G B A 1^{-1-}$ cells showed an increased GL1/GalCer ratio, whereas $G B A 1 \Delta 11$ cells had a GL1/GalCer ratio similar to that of wild-type cells (Figure 2c).

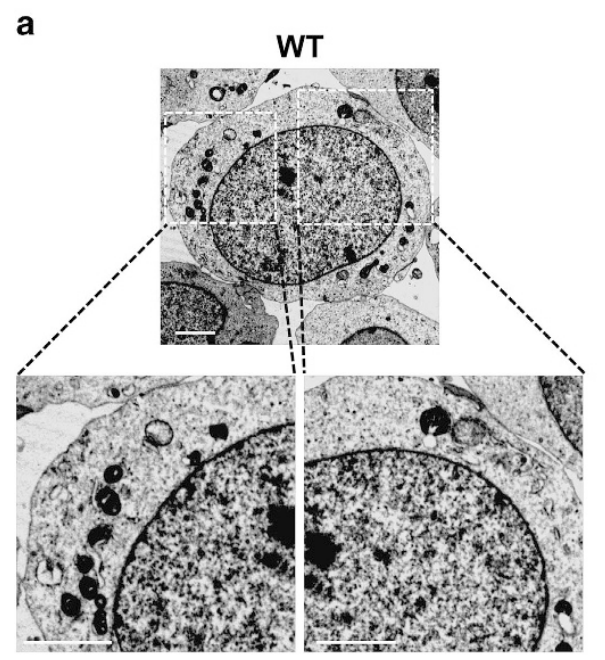

c

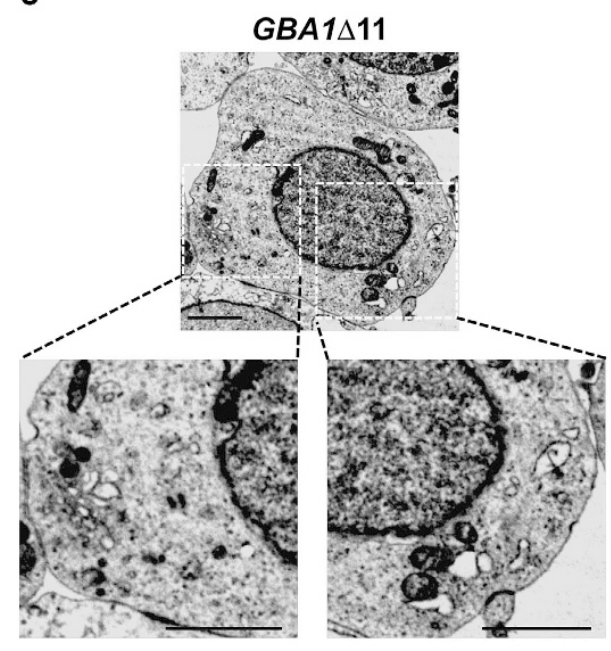

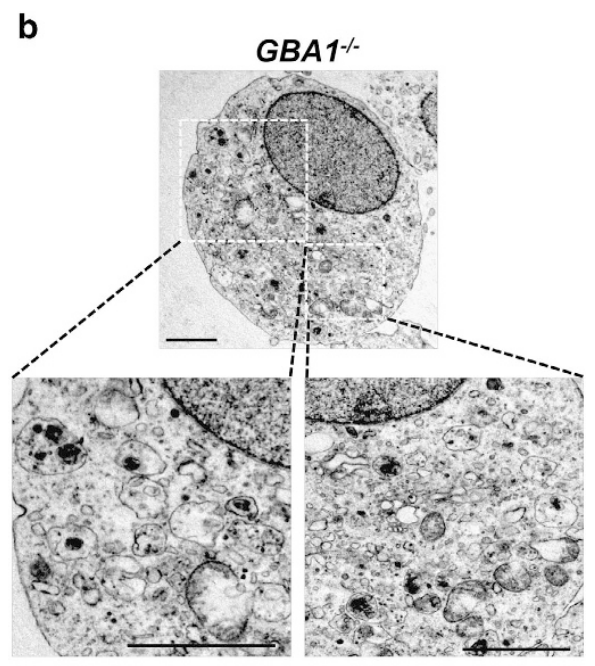

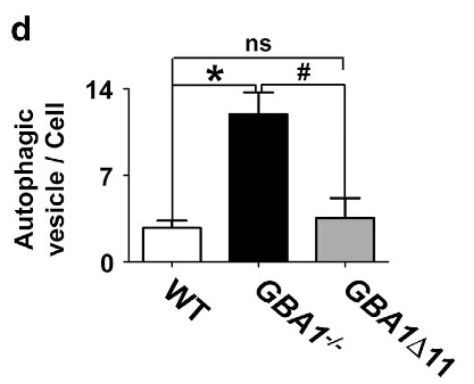

e

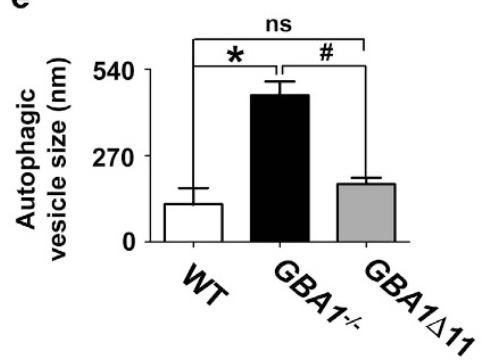

Figure 4 Vacuole accumulation due to GTP-binding protein type A1 (GBA1) deficiency. (a-c) Electron microscopy of wild-type

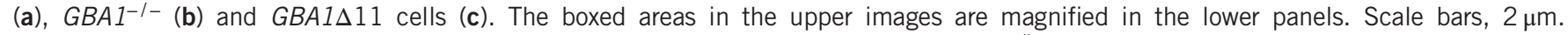
(d) Number of autophagic vesicles per cell $\left(n=3,100\right.$ cells per experiment; ${ }^{*} P<0.05,{ }^{\#} P<0.05$ by paired, two-tailed Student's $t$-test). (e) Average diameter of autophagic vesicles $\left(n=3,100\right.$ cells per experiment; ${ }^{*} P<0.05,{ }^{\#} P<0.05$ by paired, two-tailed Student's $t$-test). NS, not significant. 
a

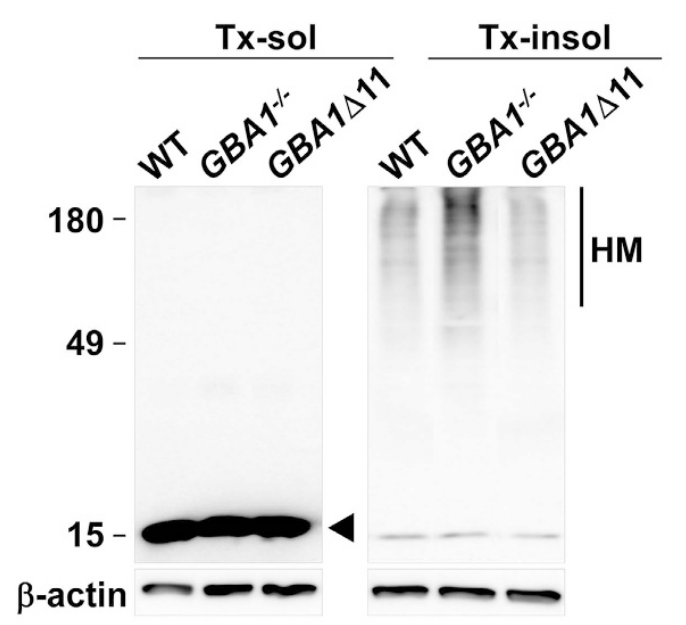

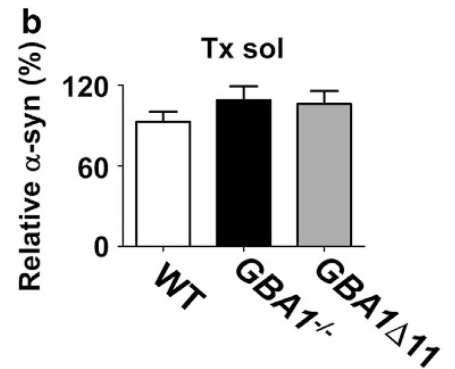

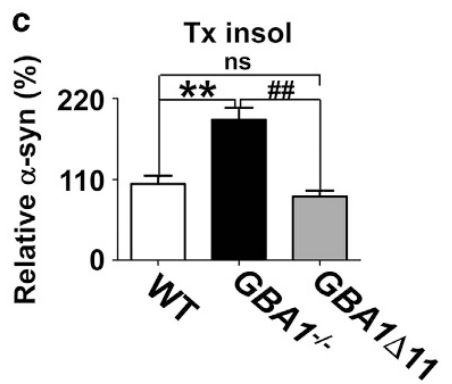

Figure 5 Glucocerebrosidase (GCase) deficiency increases accumulation of $\alpha$-synuclein aggregates. (a) Western blot analysis of $\alpha$-synuclein in Triton-soluble and Triton-insoluble fractions. HM, detergent-insoluble, high-molecular-weight $\alpha$-synuclein (the HM regions are quantified in c). Arrowhead: detergent-soluble, monomeric $\alpha$-synuclein. (b, c) Quantification of $\alpha$-synuclein in Triton-soluble (b) and Triton-insoluble fractions (c) $\left(n=3 ;{ }^{* *} P<0.01,{ }^{\# \#} P<0.01\right.$ by paired, two-tailed Student's $t$-test). NS, not significant.

a

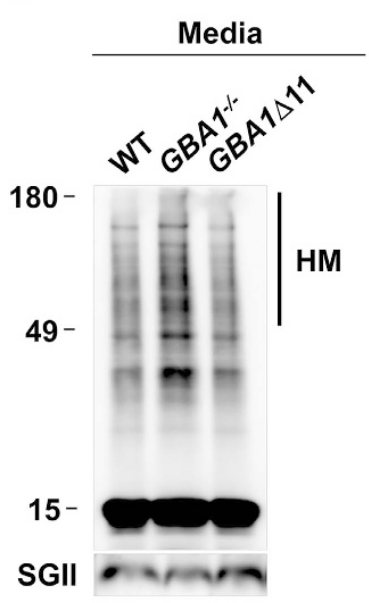

b

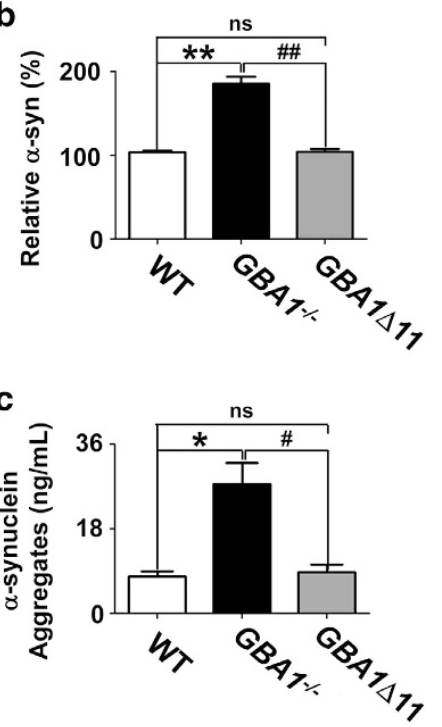

Figure 6 Secretion of $\alpha$-synuclein aggregates. (a) Western blot analysis of $\alpha$-synuclein in cell culture media. HM, high-molecularweight $\alpha$-synuclein (the HM regions are quantified in b). SGII, secretogranin II. (b) Quantification of high molecular weight $\alpha$-synuclein aggregates in culture media $\left(n=3,{ }^{*} P<0.05\right.$ by paired, two-tailed Student's $t$-test). (c) The levels of secreted $\alpha$-synuclein aggregates in cell culture media were measured using an enzymelinked immunosorbent assay specific for aggregated forms of $\alpha$-synuclein $\left(n=4 ;{ }^{*} P<0.05,{ }^{*} P<0.01,{ }^{\#} P<0.05\right.$, ${ }^{\# \#} P<0.01$ by paired, two-tailed Student's $t$ test). NS, not significant.

We next examined and compared the lysosomal functions of these cell lines. To assess lysosomal activity, we measured the levels of known lysosomal substrates (p62 and polyubiquitinated proteins) and the degradation rate of exogenously

introduced dextran. As shown in Figures 3a and b, both p62 and polyubiquitinated proteins accumulated to significantly higher levels in $G B A 1^{-/-}$cells than in wild-type cells or GBA1D11 cells. Dextran degradation was much slower in $G B A 1^{-1-}$ cells than in wild-type or GBA1D11 cells (Figure 3c). Cells with lysosomal dysfunction often show increased LysoTracker staining, probably because of both reduced breakdown of acidic organelles and increased biosynthesis of lysosomes in an effort to restore lysosomal function. ${ }^{24} G B A 1^{-1-}$ cells showed a significantly higher LysoTracker signal than wild-type or GBA1D11 cells (Figure 3d). Morphological analysis using electron microscopy confirmed lysosomal dysfunction. Compared with wild-type or GBA1D11 cells, $G B A 1^{-/-}$cells had abnormal accumulation of enlarged autophagic vesicles and damaged cellular organelles (Figure 4). These morphological changes are akin to previous findings of vacuole accumulation as a hallmark of lysosomal storage diseases. ${ }^{25}$

Lysosomes have crucial roles in the degradation of $\alpha$-synuclein through macroautophagy and chaperone-mediated autophagy. ${ }^{26,27}$ We examined accumulation of $\alpha$-synuclein in cells with $G B A 1$ mutations. Neither $G B A 1^{-1-}$ nor GBA1 11 cells showed changes in the levels of monomeric $\alpha$-synuclein compared with wild-type cells (Figures $5 a$ and $b$ ). However, $G B A 1^{-1-}$ cells accumulated SDS-stable $\alpha$-synuclein oligomers in the Triton-insoluble fractions to a greater extent than did wild-type and GBA1D11 cells (Figures $5 \mathrm{a}$ and c).

Neuronal cells secrete monomeric and oligomeric $\alpha$-synuclein, ${ }^{28}$ and the secretion of these proteins increases when cellular quality-control systems, such as the ubiquitinproteasome system and autophagy, are compromised. ${ }^{29,30}$ Consistent with these findings, secretion of $\alpha$-synuclein 
aggregates was significantly increased in $G B A 1^{-1-}$ cells compared with that in wild-type and GBA1 11 cells (Figure 6).

\section{DISCUSSION}

In the current study, we demonstrated that GBA1 deficiency caused by the targeted introduction of nonsense mutations leads to lysosomal substrate accumulation, global lysosomal dysfunction and $\alpha$-synuclein aggregation. These cellular changes are associated with the loss of GCase activity; a nonsense mutation leading to the production of a C-terminal truncated form of GCase with intact enzyme activity resulted in none of the changes observed with the GCase-deficient mutant. In a previous study, lysosomal dysfunction and accumulation of $\alpha$-synuclein and glucosylceramide, a substrate of GCase, were observed in GCase-deficient primary neurons and in induced pluripotent stem cells derived from fibroblasts of a patient with GD. ${ }^{31}$ More recently, neurons derived from induced pluripotent stem cells from patients with GBA1 mutations were shown to be defective in autophagy. ${ }^{32}$ Taken together, these results indicate that defects in lysosomal and lysosome-related functions may be an important underlying mechanism for human diseases associated with GBA1 mutations, such as PD and other LBDs.

Our study demonstrated that GBA1 deficiency can cause lysosomal dysfunction, while cells with a mutation in GBA1 that maintains GCase activity have normal lysosomal function. These results suggest that GCase activity is critical for maintaining normal lysosomal function. Consistent with our results, decreased GCase activity is associated with PD. The amount and activity of GCase were significantly reduced in several brain regions of PD patients carrying heterozygous GBA1 mutations and, more importantly, in brain regions of sporadic $\mathrm{PD}$ patients. ${ }^{33}$ Furthermore, reduction of GCase was associated with accumulation of $\alpha$-synuclein in sporadic PD. ${ }^{34}$ These studies in patients and in our cell lines provide a rationale for therapeutic approaches involving enzyme replacement and chaperoning for GCase.

The mechanism by which GBA1 mutations cause lysosomal dysfunction and neuropathy is not clearly understood. A lossof-function mechanism would predict substrate accumulation. In patients with GD, levels of glucosylsphingosine, one of the substrates of GCase, were drastically increased compared with levels of glucosylsphingosine in control subjects. ${ }^{35}$ In addition to affecting GCase substrates, GBA1 mutations may also cause global changes in cellular lipid composition. ${ }^{36}$ Our current study also showed substrate accumulation and lysosomal dysfunction in cells with GCase deficiency, supporting a lossof-function mechanism. However, when it comes to neurodegeneration, a gain-of-function mechanism may also have a role, perhaps through accumulation of misfolded GCases in the endoplasmic reticulum. ${ }^{37,38}$ Both loss-of-function and gain-offunction mechanisms may contribute to the role of GBA1 mutations in increased risk of PD. ${ }^{19}$

Neuropathological examinations of patients with dementia showed that those with LB-type pathology were more likely to carry GBA1 mutations than those with Alzheimer-type pathology, which showed no difference from control subjects. ${ }^{39}$ Furthermore, a decrease in GCase activity in the cerebrospinal fluid was observed in patients with $\mathrm{PD}^{40}$ and dementia with $\mathrm{LB}^{41}$ but not in patients with Alzheimer's disease or frontotemporal dementia. ${ }^{41}$ These results may provide insights into the origin of disease specificity. For instance, different types of lysosomal dysfunction might lead to defects in metabolism of specific disease-linked proteins. Our study showed that GBA1 deficiency increased $\alpha$-synuclein aggregation. Others have shown that mutations in GBA1 resulted in reduced $\alpha$-synuclein degradation. ${ }^{31}$ One could postulate that the effects of GBAl mutations on protein degradation are limited to a certain group of proteins that includes $\alpha$-synuclein. ${ }^{42}$ This idea needs to be validated.

In conclusion, GBA1 deficiency is sufficient to cause lysosomal dysfunction and promote $\alpha$-synuclein aggregation. These results suggest that GBA1 mutations exert pathogenic actions through a loss-of-function mechanism. Several potential mechanisms leading to $\alpha$-synuclein aggregation have been proposed. ${ }^{12}$ Elucidation of the mechanism underlying the pathogenic actions of GBA1 mutations will help us identify rational therapeutic strategies for LBDs and GD.

\section{ACKNOWLEDGEMENTS}

This work was supported by a National Research Foundation grants funded by the Korean Government (2010-0015188 to S-JL,

2013R1A1A2062861 to E-JB) and the Korea Health Technology R\&D Project, the Ministry of Health \& Welfare, Korea (HI11C1184 to S-JL).

1 Hoehn MM, Yahr MD. Parkinsonism: onset, progression and mortality. Neurology 1967; 17: 427-442.

2 Dauer W, Przedborski S. Parkinson's disease: mechanisms and models. Neuron 2003; 39: 889-909.

3 Bahr BA, Bendiske J. The neuropathogenic contributions of lysosomal dysfunction. J Neurochem 2002; 83: 481-489.

4 Trinh J, Farrer M. Advances in the genetics of Parkinson disease. Nat Rev Neurol 2013; 9: 445-454.

5 Pankratz N, Wilk JB, Latourelle JC, DeStefano AL, Halter C, Pugh EW et al. Genomewide association study for susceptibility genes contributing to familial Parkinson disease. Hum Genet 2009; 124: 593-605.

6 Satake W, Nakabayashi Y, Mizuta I, Hirota Y, Ito C, Kubo M et al. Genome-wide association study identifies common variants at four loci as genetic risk factors for Parkinson's disease. Nat Genet 2009; 41: 1303-1307.

7 Simon-Sanchez J, Schulte C, Bras JM, Sharma M, Gibbs JR, Berg D et al. Genome-wide association study reveals genetic risk underlying Parkinson's disease. Nat Genet 2009; 41: 1308-1312.

8 Edwards TL, Scott WK, Almonte C, Burt A, Powell EH, Beecham GW et al. Genome-wide association study confirms SNPs in SNCA and the MAPT region as common risk factors for Parkinson disease. Ann Hum Genet 2010; 74: 97-109.

9 Daher JP, Pletnikova O, Biskup S, Musso A, Gellhaar S, Galter D et al. Neurodegenerative phenotypes in an A53T alpha-synuclein transgenic mouse model are independent of LRRK2. Hum Mol Genet 2012; 21: 2420-2431.

10 Brady RO, Kanfer J, Shapiro D. The metabolism of glucocerebrosides. I. purification and properties of a glucocerebroside-cleaving enzyme from spleen tissue. J Biol Chem 1965; 240: 39-43.

11 Hruska KS, LaMarca ME, Scott CR, Sidransky E. Gaucher disease: mutation and polymorphism spectrum in the glucocerebrosidase gene (GBA). Hum Mutat 2008; 29: 567-583.

12 Yang NY, Lee YN, Lee HJ, Kim YS, Lee SJ. Glucocerebrosidase, a new player changing the old rules in Lewy body diseases. Biol Chem 2013; 394: 807-818. 
13 Sidransky E, Nalls MA, Aasly JO, Aharon-Peretz J, Annesi G, Barbosa ER et al. Multicenter analysis of glucocerebrosidase mutations in Parkinson's disease. N Engl J Med 2009; 361: 1651-1661.

14 Rosenbloom B, Balwani M, Bronstein JM, Kolodny E, Sathe S, Gwosdow AR et al. The incidence of Parkinsonism in patients with type 1 Gaucher disease: data from the ICGG Gaucher Registry. Blood Cells Mol Dis 2011; 46: 95-102.

15 Goker-Alpan O, Stubblefield BK, Giasson BI, Sidransky E. Glucocerebrosidase is present in alpha-synuclein inclusions in Lewy body disorders. Acta Neuropathol 2010; 120: 641-649.

16 Clark LN, Kartsaklis LA, Wolf Gilbert R, Dorado B, Ross BM, Kisselev S et al. Association of glucocerebrosidase mutations with dementia with lewy bodies. Arch Neurol 2009; 66: 578-583.

17 Lee HJ, Bae EJ, Jang A, Ho DH, Cho ED, Suk JE et al. Enzyme-linked immunosorbent assays for alpha-synuclein with species and multimeric state specificities. J Neurosci Methods 2011; 199: 249-257.

18 Lee H-J, Khoshaghideh F, Patel S, Lee S-J. Clearance of alpha-synuclein oligomeric intermediates via the lysosomal degradation pathway. J Neurosci 2004; 24: 1888-1896.

19 Sardi SP, Clarke J, Kinnecom C, Tamsett TJ, Li L, Stanek LM et al. CNS expression of glucocerebrosidase corrects alpha-synuclein pathology and memory in a mouse model of Gaucher-related synucleinopathy. Proc Nat Acad Sci USA 2011; 108: 12101-12106.

20 Lee H-J, Shin SY, Choi C, Lee YH, Lee S-J. Formation and removal of alphasynuclein aggregates in cells exposed to mitochondrial inhibitors. $J$ Bio Chem 2002; 277: 5411-5417.

21 Atrian S, Lopez-Vinas E, Gomez-Puertas P, Chabas A, Vilageliu L, Grinberg D. An evolutionary and structure-based docking model for glucocerebrosidase-saposin C and glucocerebrosidase-substrate interactions - relevance for Gaucher disease. Proteins 2008; 70: 882-891.

22 Lieberman RL. A guided tour of the structural biology of gaucher disease: acid-beta-glucosidase and saposin C. Enzyme Res 2011; 2011: 973231.

23 Cabrera-Salazar MA, Bercury SD, Ziegler RJ, Marshall J, Hodges BL, Chuang WL et al. Intracerebroventricular delivery of glucocerebrosidase reduces substrates and increases lifespan in a mouse model of neuronopathic Gaucher disease. Exp Neurol 2010; 225: 436-444.

24 Butler D, Nixon RA, Bahr BA. Potential compensatory responses through autophagic/lysosomal pathways in neurodegenerative diseases. Autophagy 2006; 2: 234-237

25 Meikle PJ, Brooks DA, Ravenscroft EM, Yan M, Williams RE, Jaunzems AE et al. Diagnosis of lysosomal storage disorders: evaluation of lysosomeassociated membrane protein LAMP-1 as a diagnostic marker. Clin Chem 1997; 43: 1325-1335.

26 Webb JL, Ravikumar B, Atkins J, Skepper JN, Rubinsztein DC Alpha-Synuclein is degraded by both autophagy and the proteasome. $J$ Biol Chem 2003; 278: 25009-25013.

27 Cuervo AM, Stefanis L, Fredenburg R, Lansbury PT, Sulzer D. Impaired degradation of mutant alpha-synuclein by chaperone-mediated autophagy. Science 2004; 305: 1292-1295.

28 Lee H-J, Patel S, Lee S-J. Intravesicular localization and exocytosis of alpha-synuclein and its aggregates. J Neurosci 2005; 25: 6016-6024.

29 Jang A, Lee HJ, Suk JE, Jung JW, Kim KP, Lee SJ. Non-classical exocytosis of alpha-synuclein is sensitive to folding states and promoted under stress conditions. J Neurochem 2010; 113: 1263-1274.
30 Lee HJ, Cho ED, Lee KW, Kim JH, Cho SG, Lee SJ. Autophagic failure promotes the exocytosis and intercellular transfer of alpha-synuclein. Exp Mol Med 2013; 45: e22.

31 Mazzulli JR, Xu YH, Sun Y, Knight AL, McLean PJ, Caldwell GA et al. Gaucher disease glucocerebrosidase and alpha-synuclein form a bidirectional pathogenic loop in synucleinopathies. Cell 2011; 146: 37-52.

32 Schondorf DC, Aureli M, McAllister FE, Hindley CJ, Mayer F, Schmid B et al. iPSC-derived neurons from GBA1-associated Parkinson's disease patients show autophagic defects and impaired calcium homeostasis. Nat Commun 2014; 5: 4028

33 Gegg ME, Burke D, Heales SJ, Cooper JM, Hardy J, Wood NW et al. Glucocerebrosidase deficiency in substantia nigra of parkinson disease brains. Ann Neurol 2012; 72: 455-463.

34 Murphy KE, Gysbers AM, Abbott SK, Tayebi N, Kim WS, Sidransky E et al. Reduced glucocerebrosidase is associated with increased alpha-synuclein in sporadic Parkinson's disease. Brain 2014; 137: 834-848.

35 Orvisky E, Park JK, LaMarca ME, Ginns El, Martin BM, Tayebi N et al. Glucosylsphingosine accumulation in tissues from patients with Gaucher disease: correlation with phenotype and genotype. Mol Genet Metab 2002; 76: 262-270.

36 Hein LK, Meikle PJ, Hopwood JJ, Fuller M. Secondary sphingolipid accumulation in a macrophage model of Gaucher disease. Mol Genet Metab 2007; 92: 336-345.

37 Ron I, Horowitz M. ER retention and degradation as the molecular basis underlying Gaucher disease heterogeneity. Hum Mol Genet 2005; 14: 2387-2398.

38 Bendikov-Bar I, Ron I, Filocamo M, Horowitz M. Characterization of the ERAD process of the L444P mutant glucocerebrosidase variant. Blood Cells Mol Dis 2011; 46: 4-10.

39 Tsuang D, Leverenz JB, Lopez OL, Hamilton RL, Bennett DA, Schneider JA et al. GBA mutations increase risk for Lewy body disease with and without Alzheimer disease pathology. Neurology 2012; 79: 1944-1950.

40 Balducci C, Pierguidi L, Persichetti E, Parnetti L, Sbaragli M, Tassi C et al. Lysosomal hydrolases in cerebrospinal fluid from subjects with Parkinson's disease. Mov Disord 2007; 22: 1481-1484.

41 Parnetti L, Balducci C, Pierguidi L, De Carlo C, Peducci M, D'Amore C et al. Cerebrospinal fluid beta-glucocerebrosidase activity is reduced in Dementia with Lewy Bodies. Neurobiol Dis 2009; 34: 484-486.

42 Xu YH, Xu K, Sun Y, Liou B, Quinn B, Li RH et al. Multiple pathogenic proteins implicated in neuronopathic Gaucher disease mice. Hum Mol Genet 2014; 23: 3943-3957.

(1) () $\odot$ This work is licensed under a Creative Commons Attribution-NonCommercial-NoDerivs 3.0 Unported License. The images or other third party material in this article are included in the article's Creative Commons license, unless indicated otherwise in the credit line; if the material is not included under the Creative Commons license, users will need to obtain permission from the license holder to reproduce the material. To view a copy of this license, visit http://creativecommons.org/licenses/by-nc-nd/3.0/ 